\title{
Educação empreendedora: um despertar para alunos do ensino médio na cidade de Araguari - MG
}

DOI: 10.47224/revista master.v6i11.109

\author{
Danilo Faria de Moura \\ Emanuel Soares Ponciano \\ Estefanie Cristina Guida de Oliveira \\ Gabriel Cardoso dos Santos \\ Laís Cristina Pereira Silva \\ Laura de Freitas Farias Oliveira \\ Lorena Medeiros Rodrigues \\ Paula Rezende Barbosa Chiovato \\ Richardson Camilo Brazao \\ Thays Marques Silva \\ Victor Souza Alves
}

e-mail:danilofmoura@yahoo.com.br

\section{Resumo}

A proposta da educação empreendedora é incluir atitudes e disciplinas no currículo escolar visando desenvolver essas habilidades, assim, quando chegarem ao mercado, os estudantes poderão aplicar esse conhecimento não só como empreendedores, mas também como executivos, autônomos, empregados ou servidores públicos. O objetivo deste estudo é despertar o interesse pelo empreendedorismo nos alunos do ensino médio e realçar a importância de abordagem sobre este assunto na sala de aula. Utilizou-se da Metodologia do Arco de Maguerez para, a partir da observação da realidade, elencar as problemáticas e desenvolver hipóteses de solução. A pesquisa bibliográfica forneceu o suporte para a fundamentação teórica, e a escolha das se deu considerando as publicações de maior relevância relacionadas ao tema. Como proposta de intervenção propôs-se que fossem realizadas palestras nas escolas sobre o empreendedorismo para os estudantes, porém com o fato que está acontecendo no mundo, o COVID-19, não foi possível realizar a intervenção em virtude ao momento de pandemia. Concluiu-se ser de extrema importância incluir o tema de empreendedorismo nas escolas para que, desde mais novos, os jovens estejam preparados para o mercado de trabalho.

Palavras-chave: Empreendedorismo; Educação Empreendedora; Empreendedorismo Corporativo.

\begin{abstract}
The proposal of entrepreneurial education is to incorporate attitudes and subjects within the school curriculum aimed toward developing these skills, in order that once they get to the market, students are going to be ready to apply this data not only as entrepreneurs, but also as executives, freelancers, employees, or public servants. the target of this study is to arouse interest in entrepreneurship among highschool students and to spotlight the importance of approaching this subject within the classroom. The Maguerez's Arc Methodology was wont to, from the observation of reality, list the issues and develop solution hypotheses. The bibliographical research provided the support for the theoretical foundation, and therefore the choice of those was made considering the foremost relevant publications associated with the theme. As an intervention proposal, it had been proposed that lectures on entrepreneurship should be held in schools for college kids, but with the very fact that's happening within the world, the COVID-19, it had been impossible to hold out the intervention thanks to the pandemic moment. it had been concluded that it's extremely important to incorporate the topic of entrepreneurship in schools in order that, from a young age, children are prepared for the market.
\end{abstract}

Keywords: $\quad$ Entrepreneurship; Entrepreneurial Education; Corporate Entrepreneurship. 


\section{INTRODUÇÃO}

Degen (1989, apud Da Costa, Wolf e Ribeiro, 2006, p. 15), responsável pela introdução do estudo do empreendedorismo no Brasil, destaca que "são raros os traços de personalidade e comportamento que se traduzem na vontade de criar coisas novas e de concretizar, na prática, ideias próprias."

Partindo dessa definição é possível acentuar o papel das escolas brasileiras na adoção de métodos de ensino que estimulem o desenvolvimento de habilidades empreendedoras, uma vez que ainda seguem currículos sistematizados que estimulam os padrões e repetições com pouca ênfase à criação e novas ideias.

O presente artigo é resultante de atividades realizadas no Curso de Administração. Sua elaboração se deu por meio da Metodologia da Problematização com o Arco de Maguerez e foi vivenciada tendo como marco norteador pela temática educação empreendedora, considerando a cidade de Araguari como delimitação geográfica para pesquisa. A pesquisa bibliográfica forneceu suporte para a fundamentação teórica, e a escolha da bibliografia e dos artigos é consistente com a temática.

Objetiva-se, por meio desse artigo, identificar, através de análise bibliográfica e pesquisas de narrativas, os fatores de sucesso e insucesso da educação estimulada ao empreendedorismo na cidade de Araguari, além de propor ações que possam propiciar melhorias para esse cenário.

Goob (2019, documento online) ressalta que "a missão da escola, além de preparar os estudantes para o mercado de trabalho, é formar cidadãos críticos e conscientes, que possam contribuir como agentes de mudança na sociedade." A autora ainda descreve que o sistema atual de educação tem um foco na passagem de conteúdo para os alunos e na medição do quanto esse conteúdo foi assimilado.

Dornelas (2018, p. 13) aponta dois tipos de empreendedorismo: Empreendedorismo por necessidade e Empreendedorismo por oportunidade. $O$ autor descreve que 0 empreendedorismo por necessidade se dá em momentos críticos como falta de oportunidades formal, demissão ou falta de recursos financeiros. Já o empreendedorismo por oportunidade decorre de um planejamento prévio, desenvolvimento de novas ideias e projetos, desejo de autonomia em uma busca voluntária ou até mesmo como projeto pós carreira.

As questões relacionadas ao empreendedorismo de necessidade acontecem independente da escolarização, algumas pessoas optam por empreender por terem essa alternativa como única opção viável, e muitas empresas iniciam assim. Já o empreendedorismo por oportunidade pode ser incentivado pela educação ao desenvolver habilidades empreendedoras, e essa vertente pode trazer contribuições muito significativas para a sociedade e para a economia.

Esse artigo justifica-se em virtude da necessidade de fomentar o empreendedorismo como uma possibilidade profissional, seja o intraempreendedorismo ou empreendedorismo para novos negócios, visto que as competências são de importância mister para o sucesso na carreira, independente de qual seja ela.

\section{IDENTIFICAÇÃO DA PROBLEMÁTICA}

De acordo com artigo publicado pelo site Brasil Escola,

\begin{abstract}
A Base Nacional Comum Curricular deverá nortear o currículo do novo ensino médio. A BNCC define os elementos obrigatórios e comuns a todas as escolas, desde a educação infantil até o ensino médio. Em abril de 2018, o MEC entregou ao Conselho Nacional de Educação (CNE) a última versão da BNCC. O documento define que a carga horária do novo ensino médio terá o total de três mil horas. Dessas, 1.800 serão destinadas ao currículo comum e 1.200 aos itinerários formativos. Apenas as disciplinas de português, matemática e língua inglesa serão obrigatórias nos três anos de curso. Para estudantes indígenas, fica garantido o ensino nas línguas maternas. (SILVA, 2018, documento online).
\end{abstract}

As mudanças previstas na matriz curricular do ensino médio objetivam dinamizar o processo para que o ensino técnico possa ser realizado concomitante ao médio, em que os alunos terão maior autonomia para definirem os rumos da sua educação, de acordo com os seus interesses e 
afinidades pessoais. Essa é uma ação que aproxima a educação à formação profissional dos alunos. A previsão para implantação dessas novas direções educacionais nas escolas era o ano de 2019, porém a grande maioria ainda não conseguiu se adaptar, principalmente as escolas públicas.

Silva (2018, documento online) relata que "o novo ensino médio representa uma reforma na estrutura do atual sistema de ensino do país." A autora ainda relara que, de acordo com o Ministério da Educação (MEC), o objetivo é aproximar os alunos das transformações do mercado de trabalho, possibilitando uma formação mais atualizada.

O desenvolvimento das habilidades reforçadas pelos autores de referência na temática somente se faz possível através de um processo educacional que atribua o protagonismo e a autorresponsabilidade dos alunos, hoje condicionados para elaborarem conclusões padrões e escolher entre questões com alternativas definidas em avaliativas com opções prontas de respostas, modelo aplicado nas escolas e nos instrumentos de medição do conhecimento.

As metodologias educacionais baseadas em problematização ativa são determinantes para uma educação significativa. $\mathrm{O}$ atual modelo de ensino é realizado por meio de aulas expositivas e alguns professores sequer permitem interrupções para contribuições durante suas explicações, gerando um clima de autoridade e represaria.

Goob (2019, documento online) reforça que "o desenvolvimento de habilidades empreendedoras tornará os alunos mais aptos a analisar problemas complexos, propor soluções inovadoras e crescer profissionalmente, seja criando seu próprio negócio ou dentro de uma empresa."

A problemática a ser explorada por esse artigo é a ausência, ou ainda tímida presença, da abordagem das competências empreendedoras na formação de alunos no ensino médio, visto que é oportuna para a primeira fase de suas carreiras profissional, culminando com a maioridade e geralmente as primeiras oportunidades no mercado de trabalho.

\section{COMPREENSÃO DA REALIDADE}

De acordo com Goob (2019, documento online) "muitas pessoas acreditam que para empreender é necessário nascer com algum tipo de talento especial, como se essa capacidade fosse um dom." Esse fator pode ser considerado uma premissa difundida nas escolas que receberam em suas educações formais e sociais a visão empreendedora como algo não possível de ser realizado por todos.

Dornelas (2018, p. 12) afirma que "o ato de empreender está ligado à ação, a pessoa deve atentar para os eventos que ocorrem em seu ambiente e que, em muitos casos, acabam por apresentar o empreendedorismo como um caminho óbvio para seu futuro." Partindo desse pressuposto entende-se que é uma habilidade a ser desenvolvida, sendo essa uma grande oportunidade nas escolas.

Para compor a observação da realidade foram analisados relatos e experiências de alunos do ensino superior referente ao processo de escolarização, observância das disciplinas curriculares e competências desenvolvidas pela escola com estudantes do ensino médio e narrativa de docentes sobre a questão tema desse artigo.

Ambas as vertentes observadas culminam questões similares relacionadas a uma educação pautada em memorização com baixo estímulo à habilidade de criatividade e de resolução de problemas, além de estigmas referentes às condições para empreender vinculadas à condição econômica em virtude de investimentos. Observa-se que a educação tem papel fundamental na formação de cidadãos críticos que possam, após seu período de escolarização, desenvolver suas vidas pessoais e profissionais fazendo contribuições sociais e para si.

Segundo o Serviço Brasileiro de Apoio às Micro e Pequenas Empresas - SEBRAE (2014, documento online) "o empreendedor tem como característica básica o espírito criativo e pesquisador." Já para Dornelas (2018, p. 22) "empreendedorismo é o envolvimento de pessoas e processos que, em conjunto, levam a transformação de ideias em oportunidades."

Dolabela (2006, p. 13) sinaliza alguns motivos para se estimular a cultura empreendedora como o faro do empreendedorismo oferecer graus elevados de autorrealização e o desenvolvimento econômico. 0 autor destaca que um importante motivo é reorientar o ensino brasileiro para as novas relações de trabalho, não mais voltadas para o emprego, os colégios técnicos e as universidades precisam preparar profissionais com alto grau de empreendedorismo, capazes de buscar soluções por 
si mesmos, de definir e perseguir um sonho, se auto motivar, se adaptar a mudanças e ter um olhar amplo sobre a empresa e o mercado.

Diante dos pontos expostos foram relacionados os possíveis fatores imediatos e os condicionantes maiores, associados ao problema em questão.

Possíveis fatores imediatos:

- Formação educacional defasada com as necessidades do mercado;

- Baixa inclinação social para o empreendedorismo;

- Não aproveitamento das oportunidades para atendimento à novas necessidades sociais por meio de negócios inovadores.

Possíveis condicionantes maiores:

- Insucesso na empreitada profissional desde os primeiros passos da carreira;

- Formação educacional insatisfatória para promoção de competências técnicas e profissionais;

- Falta de incentivo à criatividade e resolução de problemas, e consequentemente ao empreendedorismo.

A reflexão sobre os fatores imediatos e os condicionantes maiores, associados ao problema, evidencia alguns aspectos essenciais ou pontoschave:

- Educação empreendedora no ensino médio

- Desenvolvimento de competências empreendedoras na formação para a vida;

- Métodos de ensino estimulantes e atrativos.

\section{EDUCAÇÃO EMPREENDEDORA NO ENSINO MÉDIO}

Para melhor compreensão sobre o incentivo ao empreendedorismo no Brasil nas escolas, buscou-se uma fundamentação teórica que propiciasse um maior embasamento a respeito dos pontos-chave levantados e que, consequentemente, pudesse conduzir às hipóteses de solução para o problema eleito.

Esses aspectos foram objetos de uma revisão da literatura, aferindo se a educação empreendedora é necessária para potencializar habilidades e competências cada vez mais valorizadas no mundo dos negócios.

Barreto (1998, apud Da Costa Da Costa, Wolf e Ribeiro, 2006, p. 14) define empreendedorismo como "a habilidade de se conceber e estabelecer algo partindo de muito pouco ou quase nada". Esse ponto amplia as possibilidades da educação para considerar os aspectos empreendedores na formação dos alunos, e consequentemente da sociedade.

Nos anos recentes, países de todo o mundo vêm debatendo sobre a importância do empreendedorismo na vida das pessoas desde o ensino médio, para que os adolescentes tenham um preparo para encarar o mercado de trabalho.

Muitas pessoas inferem que saber empreender é apenas abrir um negócio, porém vai muito além disso, o que ainda desconhecem, pois não são ensinadas quando ainda mais jovens.

\begin{abstract}
Um empreendedor é uma pessoa que imagina, desenvolve e realiza visões, além de ser uma pessoa criativa, marcada pela capacidade de estabelecer e atingir objetivos, mantendo um nível de consciência do ambiente em que vive e utilizando-o para detectar oportunidades de negócios. (FILION, 1999, p. 19)
\end{abstract}

Diante dessa situação, foram criados cursos para jovens que se interessam no assunto e querem aprender mais sobre empreendedorismo. O Sebrae disponibiliza cursos gratuitos em seu site para estudantes do ensino médio que têm interesse em ter uma educação empreendedora inserida na sua formação.

De acordo com informações vinculadas no site do Sebrae (2014, documento online) "O Formação de Jovens Empreendedores (FJE) é um curso para estudantes do ensino médio que têm interesse em ter uma educação empreendedora inserida na sua formação escolar. O curso mostra que é possível aprender a empreender." 


\section{DESENVOLVIMENTO DE COMPETÊNCIAS EMPREENDEDORAS NA FORMAÇÃO PARA A VIDA}

Para Dornelas (2018, p. 11) “empreender não se resume à criação do negócio próprio, mas a maneira mais conhecida de se tornar um empreendedor é criando uma empresa." O autor ainda afirma que "com a disseminação do conceito de empreendedorismo na sociedade, o comportamento empreendedor passou a ser observado com mais atenção em ambientes nos quais antes não se pensava haver empreendedores" (DORNELAS, 2018, p. 11). Dornelas exemplifica em sua obra intitulada "Introdução ao empreendedorismo - Desenvolvendo habilidades para fazer acontecer" diversas atividades empreendedoras possibilitadas em campos distintos através do comportamento social em busca de mudanças e melhorias.

Ainda se questiona se o empreendedor nasce com as características relacionadas ao negócio ou se são desenvolvidas ao longo da vida. Após várias pesquisam acredita-se que essas competências podem ser desenvolvidas, principalmente sendo reflexo das condições e estímulos do meio em que vivem.

Giib (1987, apud Sarkar, 2010, p. 61), defende que durante a infância a criança recebe influência dos pais ou da família e do meio em que convive para desenvolver habilidades empreendedoras. Esses fatores podem ser representados pela situação de trabalho dos pais, além dos valores familiares e seus objetivos de vida. $O$ autor ainda descreve que durante a adolescência a educação ganha papel de destaque por meio dos métodos educacionais ao qual a pessoa é exposta, influenciando suas preferências vocacionais. Já na fase adulta o autor relata que a formação continua influenciando nas escolhas e possibilidades, assim como a comunidade em que vive e a natureza do trabalho. Por fim o autor descreve que na meia-idade a situação familiar e rendimentos fazem com que a pessoa opte por possibilidades de renda extra, fazendo aflorar suas habilidades empreendedoras pela necessidade emergente.

Para ser um bom empreendedor é necessário ter algumas habilidades como negociação, avaliar o comportamento do consumidor entre outras. Esses fatores podem ser aprendidos participando de cursos específicos. Também é possível aprender explorando o conhecimento de outras pessoas. A busca pelo desenvolvimento pessoal também é uma maneira de desenvolver o empreendedorismo.

A introdução da educação empreendedora ao nível pós-secundário é influenciada pela presença de fatores de mercado e ambientais, que determinam a natureza da resposta empreendedora. 0 ambiente pode requerer um maior ou menor nível empreendedor. Quando o nível empreendedor exigido é reduzido, a escolha de incorporar modelos de educação empreendedora aparece. Pelo contrário, se é elevado, esse programa torna-se uma necessidade. (SARKAR, 2010, p. 84)

\section{MÉTODOS DE ENSINO ESTIMULANTES E ATRATIVOS}

De acordo com Coan (2003, p. 2) "a necessidade de formar pessoas com espírito empreendedor, principalmente por meio da educação escolar em todos os níveis e modalidades de ensino, vem se difundindo muito rapidamente, tanto por meio de pesquisas, como por meio de realização de projetos práticos."

O autor ainda discorre que:

O espaço escolar é disputado como lócus para formar um trabalhador de novo tipo, convencido de estar apto a enfrentar os desafios do atual mercado de trabalho vendendo sua força de trabalho sob diversos moldes, quer seja prestando serviços, fazendo consultorias, realizando trabalho terceirizado, temporário, a domicílio, subcontratado, quer seja com bolsas de estudo, estágio ou arranjos flexíveis e precários similares. (COAN, 2003, p. 2)

Para Moran (2015, p. 15) "a educação formal está num impasse diante de tantas mudanças na sociedade: como evoluir para tornar-se relevante e conseguir que todos aprendam de forma competente a conhecer, a construir seus projetos de vida e a conviver com os demais." O autor questiona os métodos de ensino utilizados em que a aula expositiva não possibilita a experimentação e 
vivência de situações, assim como a resolução de problemas, para se tornar um aprendizado mais significativo. $O$ autor ressalta que "os métodos tradicionais, que privilegiam a transmissão de informações pelos professores, faziam sentido quando o acesso à informação era difícil" (MORAN, 2015, p. 16).

Moran (2015, p. 18) propõe que "quanto mais aprendamos próximos da vida, melhor." Uma alternativa sugerida pelo autor é a utilização de metodologias ativas, que segundo ele "são pontos de partida para avançar para processos mais avançados de reflexão, de integração cognitiva, de generalização, de reelaboração de novas práticas"(MORAN, 2015, p. 18).

Alguns componentes são fundamentais para o sucesso da aprendizagem: a criação de desafios, atividades, jogos que realmente trazem as competências necessárias para cada etapa, que solicitam informações pertinentes, que oferecem recompensas estimulantes, que combinam percursos pessoais com participação significativa em grupos, que se inserem em plataformas adaptativas, que reconhecem cada aluno e ao mesmo tempo aprendem com a interação, tudo isso utilizando as tecnologias adequadas. (MORAN, 2015, p. 18)

Certamente a utilização de jogos e atividades que simulem a realidade contribuem para que a aprendizagem se torne mais atrativa e significativa. A educação deve deixar de ser um fardo aos estudantes, ela pode ser prazerosa e atingir resultados satisfatórios. Moran (2015, p. 20) propõe que "as escolas como um todo precisam repensar esses espaços tão quadrados para espaços mais abertos, onde lazer e estudo estejam mais integrados."

Uma educação empreendedora aliada a metodologias que façam a transposição do conteúdo para a realidade do aluno certamente irá apoiar na transformação da sociedade com o desenvolvimento de habilidades e competências relevantes para os novos modelos de negócios.

\section{HIPÓTESES DE SOLUÇÃO DO PROBLEMA}

Após o desenvolvimento da pesquisa por meio da livros, artigos e sites especializados na temática, elencou-se possibilidades de intervenções que podem contribuir com o enfrentamento dos problemas levantados e identificados com a observação da realidade:

- Capacitações para professores do ensino médio referente às metodologias de ensino e o empreendedorismo;

- Criação de aplicativo educativo voltado para alunos do ensino médio com a finalidade de desenvolver competência empreendedoras;

- Feira de empreendedorismo a ser realizada nas escolas que possuem ensino médio para promoção da temática;

- Palestra em escolas sobre as possibilidades que o empreendedorismo apresenta para a vida e carreira dos estudantes.

Com as hipóteses de solução levantadas analisou-se a viabilidade para a sua implementação.

\section{APLICAÇÃo À REALIDADE}

Em função da pandemia da COVID-19 as escolas estiveram em período de quarentena para que o isolamento e distanciamento social fossem efetivos na minimização da disseminação do coronavírus. Assim, não foi possível a realização da aplicação proposta relatada a seguir.

Diante as possibilidades levantadas elegeu-se a realização de palestras sobre a temática para estimular o empreendedorismo nos alunos do ensino médio na cidade de Araguari. Essa decisão foi pautada nas variáveis de complexidade de execução considerando os investimentos financeiros e de tempo, além do processo burocrático e conhecimento técnico necessário para as demais opções.

A palestra tem o intuito de apresentar os conceitos básicos de empreendedorismo, a diferença entre criatividade e inovação, além do cenário promissor para se empreender considerando os mitos e verdades acerca da temática. 
A proposta é que a palestra seja realizada antes ou depois do intervalo de aulas, para que assim, durante o período fora de salas, sejam socializados com os alunos materiais informativos, além de casos de sucesso da cidade.

Como medida paliativa será confeccionado e vinculado em redes sociais um vídeo com explanações sobre a temática tendo como base os conteúdos com os quais os autores tiveram acesso durante o curso de Administração, o que certamente irá contribuir, mesmo que de forma singela, para a promoção do assunto.

\section{CONSIDERAÇÕES FINAIS}

Compreende-se que é de extrema importância incluir o tema de empreendedorismo nas escolas para que, desde mais novos, os jovens estejam preparados para o mercado de trabalho. É relevante aprender a resolver problemas, correr riscos, mudar o que for necessário, fazer errar, aprender com os erros e tentar de novo.

Kaufmann (1990, apud Ortega, 2016, p. 122) enfatiza que "a capacidade empreendedora está na habilidade de inovar, de se expor a riscos de maneira inteligente, e de se ajustar às rápidas e contínuas mudanças do ambiente de forma rápida e eficiente." Entende-se, com a fala do autor, que as habilidades empreendedoras transcendem o campo da administração de empresas, estando presente no desenvolvimento de competências para a vida.

O desenvolvimento deste artigo possibilitou aos autores o aprofundamento na temática, perfazendo as dificuldades detectadas em uma possível problemática social. 0 entendimento das possibilidades relacionadas ao sistema de ensino para o desenvolvimento de culturas de atitudes empreendedoras nas empresas certamente é de grande importância para a comunidade local, visto que a economia e a sociedade são beneficiadas com o desenvolvimento das instituições, consequentes do posicionamento de seus colaboradores.

Mantendo essa afirmação, em momento oportuno será realizada a visita in loco à escola com o intuito de levar informação sobre o empreendedorismo com mais clareza para que os alunos tenham um primeiro contato com o tema antes de ingressarem na universidade.

\section{REFERÊNCIAS}

COAN, Marival. Educação para o empreendedorismo como estratégia para formar um trabalhador de novo tipo. 2013.

DA COSTA, Pedro; WOLF, Sérgio Machado; RIBEIRO, Tatiana VA. Empreendedorismo e educação empreendedora: confrontação entre a teoria e prática. Revista de Ciências da Administração, v. 8, n. 15, p. 09-29, 2006.

DOLABELA, Fernando. 0 segredo de Luísa: uma ideia, uma paixão e um plano de negócios: como nasce o empreendedor e se cria uma empresa. 14. ed. São Paulo: Cultura, 2006.

\section{DORNELAS, José. Introdução ao}

empreendedorismo - Desenvolvendo habilidades para fazer acontecer. São Paulo: Empreende, 2018.

FILION, L. J. Empreendedorismo: empreendedores e proprietários gerentes de pequenos negócios. Revista de Administração de empresas da Universidade de São Paulo. São Paulo, 1999.

\section{GOOB, Carla. Entenda a importância do} empreendedorismo na escola. Disponível em: $<$ https://educacao.imaginie.com.br/empreendedor ismo-na-educacao/>. Acesso em: 28 abr. 2020.

ORTEGA, Luciane Meneguin. Programa Empreendedorismo-Escola: influenciando a Universidade por meio do tripé ensino, pesquisa e extensão. Revista de Administração, Contabilidade e Economia da Fundace, v. 7, n. 1, 2016, p. 119 132.

Serviço brasileiro de apoio às micro e pequenas empresas - SEBRAE. Disponível em: http://www.sebrae.com.br/br/home/index.asp/. Acesso em: 28 abr. 2020.

MORAN, José. Mudando a educação com metodologias ativas. Coleção mídias contemporâneas. Convergências midiáticas, educação e cidadania: aproximações jovens, v. 2, n. 1, p. 15-33, 2015.

Educação Empreendedora para o seu Ensino Médio. Sebrae Nacional, 2014. Disponível em 
https://www.sebrae.com.br/sites/PortalSebrae/se braeaz/educacao-empreendedora-para-o-seuensino-

medio,07e9fbe6d9176410VgnVCM2000003c74010

aRCRD. Acesso em 15 jun. 2020.

\section{SARKAR, Soumodip. Empreendedorismo e}

inovação. Escolar Editora, 2010.

SILVA. Gabriele. Novo ensino médio: o que é importante saber. Educa Brasil, 2018. Disponível em:

https://www.educamaisbrasil.com.br/educacao/no ticias/novo-ensino-medio-o-que-e-importantesaber. Acesso em: 28 abr. 2020. 